\title{
molecules
}

ISSN 1420-3049

http://www.mdpi.org

\author{
Full Paper
}

\section{Characterization of Flavonoid Subgroups and Hydroxy Substitution by HPLC-MS/MS}

\author{
Dimitrios Tsimogiannis ${ }^{1, *}$, Martina Samiotaki ${ }^{2}$, George Panayotou ${ }^{2}$ and \\ Vassiliki Oreopoulou $^{1, *}$
}

${ }^{1}$ National Technical University of Athens, School of Chemical Engineering, 9 Iroon Polytehniou st, Zografou Campus, 157 80, Athens, Greece; Tel: +302107723166, Fax: +302107723163.

2 Biomedical Sciences Research Center “Alexander Fleming”, 34 Fleming st, 16672, Vari, Greece

* Authors to whom correspondence should be addressed; E-mail: ditsimog@chemeng.ntua.gr; vasor@chemeng.ntua.gr

Received: 15 January 2007; in revised form: 13 March 2007 / Accepted: 14 March 2007 / Published: 21 March 2007

\begin{abstract}
HPLC-DAD coupled with mass spectrometry in the positive ionization mode was applied to study the fragmentation of twelve selected flavonoids. Compounds belonging to all the major subgroups found in common plants, i.e. flavonols, flavones, dihydroflavonols, flavanones and flavanols were studied. Compound standards were injected into the spectrometer and produced characteristic mass spectra. The fragmentation of each compound was studied and it was shown that the dehydration and carbon monoxide losses from the $[\mathrm{M}+\mathrm{H}]^{+}$ion by the members of each subgroup produced specific fragments, thus allowing the characterization of the flavonoid subgroups. Moreover, fragments resulting from fission of the C-rings are specific of each subgroup and revealed the substitution pattern of A- and B-rings. In order to verify the identifying efficiency of the positive ionization mode through these characteristic fragmentations, the unknown flavonoids of an Origanum vulgare diethyl ether extract were separated with the HPLC system and the major peaks were successfully identified with the mass spectrometer.
\end{abstract}

Keywords: HPLC-MS/MS analysis, flavonoids, Origanum vulgare 


\section{Introduction}

Flavonoids are widely distributed phenolic compounds in the plant kingdom. They occur in all parts of plants as complex mixtures of different components. Their structure, consisting of two hydroxy substituted aromatic rings joined by a three carbon link (a $C_{6}-C_{3}-C_{6}$ configuration) renders them hydrogen and electron donors. Thus, they are effective scavengers of free radicals, which are intermediate products of lipid peroxidation, and they slow down oxidation reactions. The antioxidant activity of flavonoids has been studied in lipid substrates, as well as in relation to human health, in particular with regards to retarding the aging of cells and protecting against certain illnesses such as cardiovascular or coronary disease and cancer [1].

The antioxidant activity of flavonoids is related to their structure (Figure 1), especially the hydroxy substitution of the aromatic A- and B-rings and the substitution pattern of the C-ring [2-4]. According to the structure of the C-ring, five major subgroups are distinguished: flavonols (with a 2,3-double bond, 3-OH and 4-keto groups), flavones (with a 2,3-double bond and 4-keto group), dihydroflavonols or flavanonols (with 3-OH and 4-keto groups), flavanones (with 4-keto groups) and flavanols (with 3$\mathrm{OH}$ groups). It is well known that the polyhydroxy substituted flavonoids commonly found in most plants present the highest antioxidant activity, while the most favorable structural characteristic appears to be the $\mathrm{o}$-di-OH substitution of the B-ring. Free radicals can abstract the two hydroxyl hydrogens of this ring, producing the corresponding inactive quinones. However, the structure of the C-ring plays an important role in this activity; catecholic flavonols with a fully substituted C-ring present significantly higher antioxidant activity than the other members, a feature attributed to regeneration of the catechol moiety [3,5].

\section{Figure 1.}

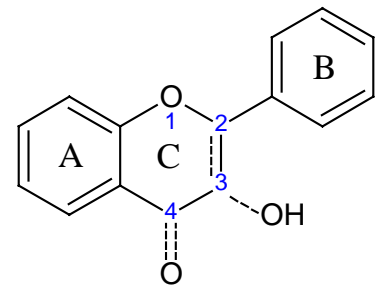

Flavonoids are usually isolated as mixtures from several plants and then tested as antioxidants. The isolation and identification of each compound, as well as the correlation of their structures to the observed activity is often difficult, due to similarities of their structures and polarities. Notable recent advances have been made in both analysis and identification of flavonoids due to the combination of instrumentation such as powerful liquid chromatographs and mass spectrometers. Specific diagnostic fragments of the A- and B-rings have been detected, while the identification of unknown flavonoids can be based additionally on their UV-Vis spectra and the correlation with standard compounds [6].

The typical UV-Vis spectra of flavonoids include two absorbance bands. Band A lies in the 310$350 \mathrm{~nm}$ range for flavones, while for flavonols it is between 350 and $385 \mathrm{~nm}$. Band $\mathrm{B}$, found in the 250-290 nm range, is much the same in all the aforementioned flavonoid subgroups. In flavanones and dihydroflavonols, band $\mathrm{A}$ is often reduced to little more than a shoulder at 300-330 nm and band $\mathrm{B}$, in the 277-295 nm range, is the main peak [7]. Consequently, these two subgroups cannot be distinguished by simple UV-Vis analysis. Flavanols show maximum absorbance at non specific 
wavelengths between 270 and $290 \mathrm{~nm}$, at which many phenolics absorb, thus not allowing their selective detection. According to these data the UV-Vis spectra can be used as an indicative tool for the characterization of C-ring, whereas the MS spectra could provide additional, significant information.

Several researchers have presented results on MS/MS analyses of flavonoid aglycones, but the elaboration of fragmentation data are not adequate to facilitate the identification of the subgroups of the examined compounds. Although losses of small molecules and/or radicals from the $[\mathrm{M}+\mathrm{H}]^{+}$ion such as those of 18 a.m.u. $\left(\mathrm{H}_{2} \mathrm{O}\right), 28$ a.m.u. (CO), 42 a.m.u. $\left(\mathrm{CH}_{2} \mathrm{CO}\right)$ are commonly observed [8], the characterization of the structures of the C-rings are usually based on the UV-Vis spectra or the information obtained by spectral libraries and the use of standards, which are not always available.

In the present study a systematic positive ionization mode HPLC-ESI-MS/MS analysis of flavonoids belonging to all the different subgroups was attempted, in order to correlate the fragmentation patterns with the structural characteristics. Typical representatives of each subgroup were selected, including compounds with different hydroxy-substitution patterns on the A- and/or Brings. The data were correlated with the work of other researchers, while fragmentation data of flavonol and taxifolin, which have not been previously reported, are presented here for the first time. The results suggest that the structure of an unknown hydroxy-substituted flavonoid aglycone can be identified by its specific fragmentation pattern combined with molecular weight and UV spectra data. Origanum vulgare, a plant rich in flavonoid antioxidants, was used as a source of flavonoid components for identification to test this hypothesis.

\section{Results and Discussion}

A series of standard hydroxy-substituted flavonoids was studied so that the fragmentation patterns of each subgroup could be verified without any additional influences of methoxy groups. Exceptionally hesperetin, a methoxyflavanone, was also used. The structures of the four flavonols (quercetin, fisetin kaempferol, flavonol), three flavones (luteolin, apigenin, chrysin), two flavanones (eriodictyol, hesperetin), two flavanols [(+)-catechin, (-)-epicatechin], and the dihydroflavonol taxifolin that were used, are presented in Figure 2.

Figure 2. The structures of the standard flavonoids studied.

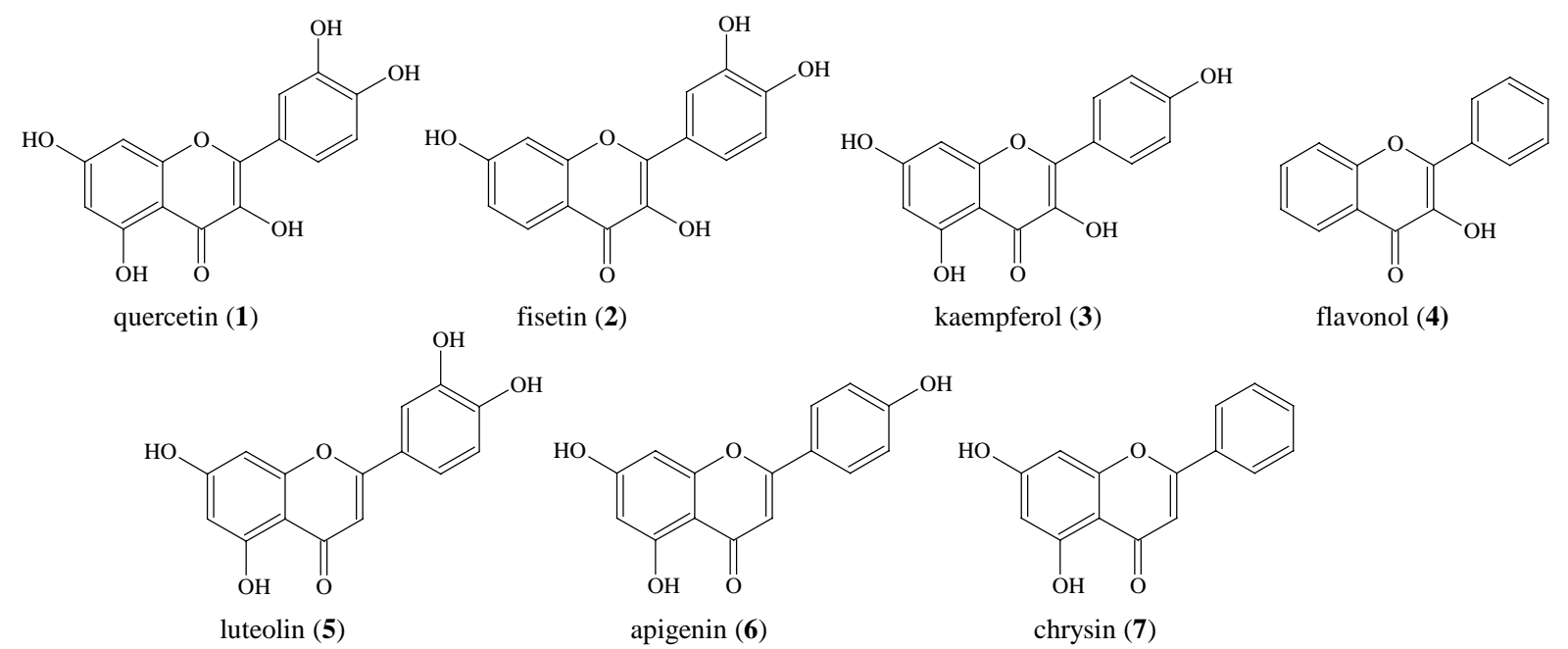


Figure 2. Cont.

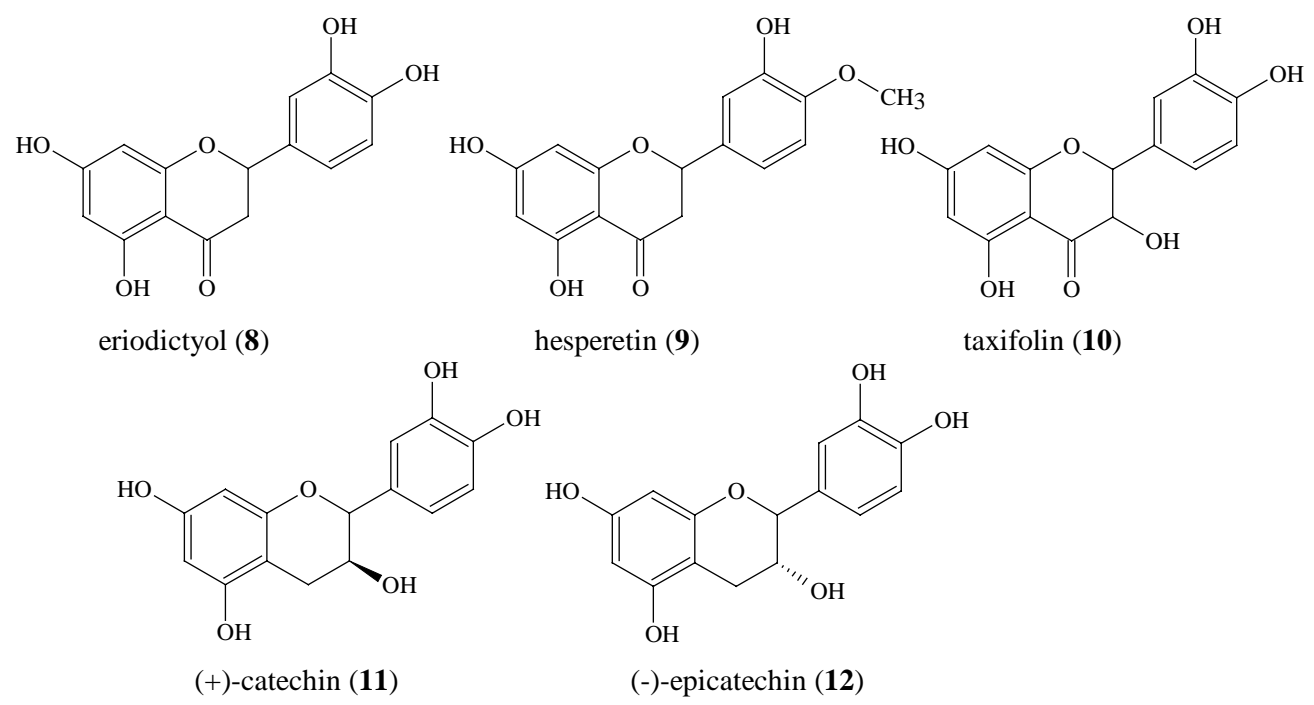

Each standard flavonoid was diluted either in acetonitrile-water (1:1) or in isopropanol at a concentration of $4 \cdot 10^{-5} \mathrm{M}$. The retention times in the HPLC-DAD analysis as well as the UV-Vis characteristics of the studied compounds are presented in Table 1.

Table 1. The retention times as well as the spectral characteristics (UV) of the standards and the isolated flavonoids from oregano.

\begin{tabular}{|c|c|c|c|c|c|c|c|}
\hline \multirow{2}{*}{$\begin{array}{l}\text { Standard } \\
\text { compound }\end{array}$} & \multirow{2}{*}{$\begin{array}{l}\text { R.t. } \\
(\mathrm{min})\end{array}$} & \multicolumn{2}{|c|}{$\begin{array}{l}\text { Absorbance } \\
\text { maxima (nm) }\end{array}$} & \multirow{2}{*}{$\begin{array}{l}\text { oregano } \\
\text { flavonoid }\end{array}$} & \multirow{2}{*}{$\begin{array}{l}\text { R.t. } \\
\text { (min) }\end{array}$} & \multicolumn{2}{|c|}{$\begin{array}{c}\text { Absorbance } \\
\text { maxima (nm) }\end{array}$} \\
\hline & & Band $A$ & Band B & & & Band A & Band B \\
\hline quercetin (1) & 43.0 & 372 & 256 & $\mathbf{A}$ & 27.3 & 340 (sh) & 288 \\
\hline fisetin (2) & 40.1 & 362 & 248 & B & 35.1 & 334 (sh) & 292 \\
\hline kaempferol (3) & 44.7 & 366 & 267 & C & 40.0 & 336 (sh) & 288 \\
\hline flavonol (4) & 51.8 & 344 & 240 & D & 43.5 & 332 (sh) & 290 \\
\hline luteolin (5) & 42.4 & 350 & 254 & & & & \\
\hline apigenin (6) & 47.0 & 336 & 269 & & & & \\
\hline chrysin (7) & 49.1 & 314 & 268 & & & & \\
\hline eriodictyol (8) & 39.5 & 336 (sh) & 288 & & & & \\
\hline hesperetin (9) & 45.4 & 336 (sh) & 288 & & & & \\
\hline taxifolin (10) & 27.5 & 340 (sh) & 288 & & & & \\
\hline$(+)$-catechin (11) & 13.5 & - & 280 & & & & \\
\hline (-)-epicatechin (12) & 19.8 & - & 278 & & & & \\
\hline
\end{tabular}

The MS/MS analysis in the present study revealed that each subgroup exhibits a characteristic fragmentation behavior, which includes, as far as the protonated molecule is concerned, dehydration, loss of $\mathrm{CO}$ and fission of the C-ring. Any unknown flavonoid aglycone can be directly classified as belonging to a particular subgroup (i.e. identification of its C-ring structure), according to the pattern 
of dehydration and $\mathrm{CO}$ losses of both the protonated molecule and produced ions. The relative abundance of these fragments is highly associated with the applied collision energy. If the collision energy is low the main fragment in the $\mathrm{MS}_{2}$ spectra produced is the $[\mathrm{M}+\mathrm{H}]^{+}$, i.e. the protonated molecule cannot be totally fragmented, while the fragments resulting from dehydration and CO losses are negligible. By increasing the collision energy a complete fragmentation of the protonated molecule is obtained. For example, the $\mathrm{MS}_{2}$ spectra of flavonol for normalized collision energies of $40 \%$ (a) and $45 \%$ (b) are presented in Figure 3; obviously, the relative abundance of the fragments produced by the $[\mathrm{M}+\mathrm{H}]^{+}$ion increased. The negative ionization mode does not produce characteristic fragments for each flavonoid subgroup as may be deduced from the previously published mass spectra for a series of flavonols, flavones and flavanones [9-13].

Figure 3. The $\mathrm{MS}_{2}$ spectrum of flavonol for normalized collision energies of $40 \%$ and $45 \%$.
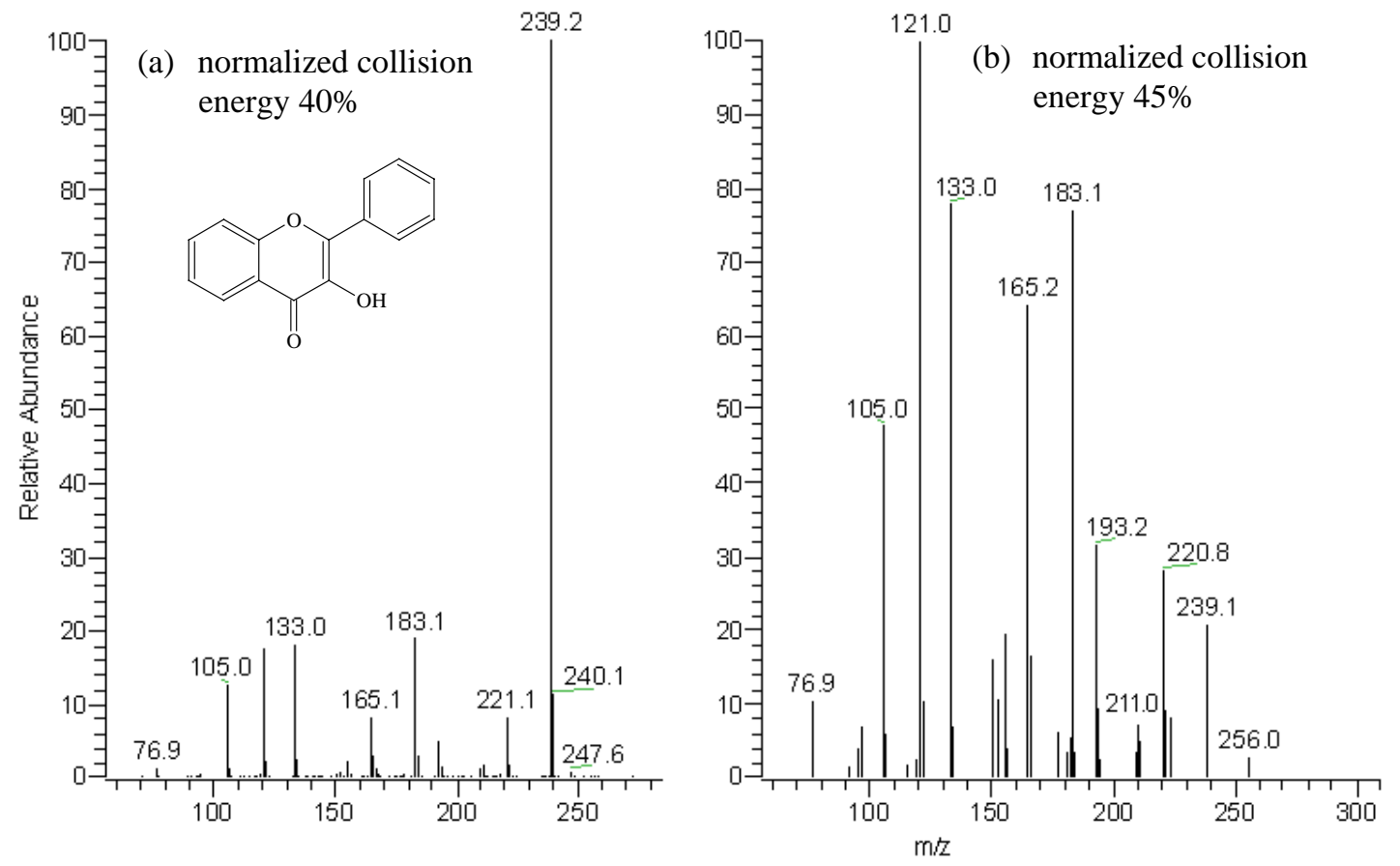

Fission is based on the retro Diels-Alder (RDA) cleavage of C-ring bonds, while the resulting fragments reveal the substitution of the A- and B-rings. According to the nomenclature of Ma et al. [14] each fragment is denoted by the combined use of ${ }^{i, j} A^{+}$or ${ }^{i, j} B^{+}$. A and $B$ represent the intact ring while the superscript on the left indicates the broken bonds of the protonated molecule. The retrocyclization cleavages of C-ring obtained for a representative compound of each flavonoid subgroup are summarized in Scheme 1, while the MS fragmentation results of all studied flavonoids are presented in Table 2. The obtained fragments are typical for each flavonoid subgroup and can provide further evidence for the characterization of the examined compound.

Flavonol $[\mathrm{M}+\mathrm{H}]^{+}$product ions dehydrated to $\left[\mathrm{M}+\mathrm{H}-\mathrm{H}_{2} \mathrm{O}\right]^{+}$, followed by two sequential losses of CO: $\left[\mathrm{M}+\mathrm{H}-\mathrm{H}_{2} \mathrm{O}-\mathrm{CO}\right]^{+}$and $\left[\mathrm{M}+\mathrm{H}-\mathrm{H}_{2} \mathrm{O}-2 \mathrm{CO}\right]^{+}$. These losses of carbon monoxide were also observed directly from the protonated flavonoid: $[\mathrm{M}+\mathrm{H}-\mathrm{CO}]^{+}$and $[\mathrm{M}+\mathrm{H}-2 \mathrm{CO}]^{+}$. The existence of the above fragments has been displayed in the mass spectra of kaempferol, galangin, quercetin and myricetin in the work of other researchers, who also collected data in positive-ion mode [10,11, 14, 15]. We examined flavonols with different number of hydroxy substituents and the results showed that all of 
them, even flavonol, which lacks hydroxy-substitution of A and B-ring (compound 4), fragmented similarly, a fact which indicates that the loss of CO and dehydration occur in the C-ring and proves the flavonol structure of the C-ring of an unidentified flavonoid. Furthermore the C-ring degraded by cleavage of bonds 0,2 and 1,3 and produced the respective RDA fragments $\left({ }^{0,2} \mathrm{~A}^{+},{ }^{0,2} \mathrm{~B}^{+}\right.$and ${ }^{1,3} \mathrm{~A}^{+}$, ${ }^{1,3} \mathrm{~B}^{+}$) of the protonated molecule.

Scheme 1. The observed retrocyclization cleavages of the C-ring and the resulting fragments for $5,7,3^{\prime}, 4^{\prime}$-hydroxy-substituted compounds.

$(+)$-Catechin (flavanol) $[\mathrm{M}+\mathrm{H}]^{+}=273$

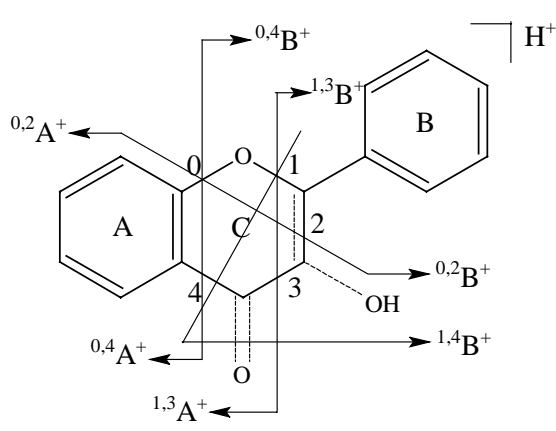

Quercetin (flavonol) $[\mathrm{M}+\mathrm{H}]^{+}=303$

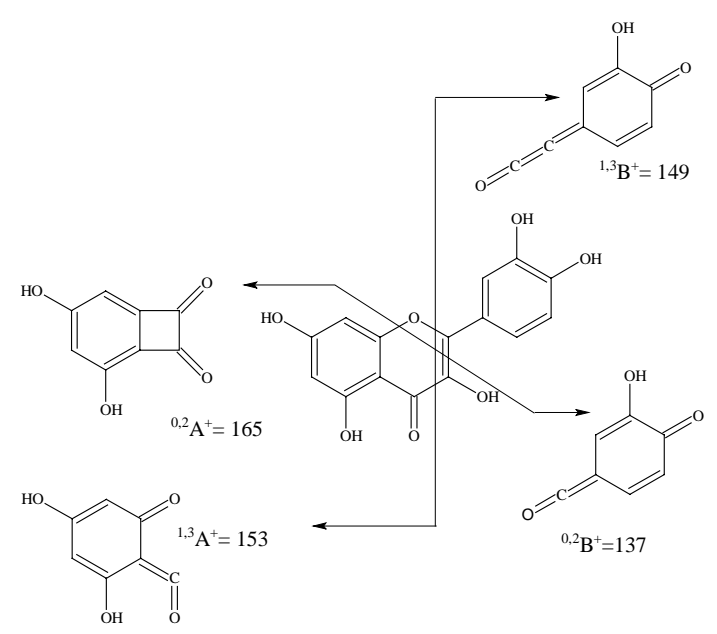

Luteolin (flavone) $[\mathrm{M}+\mathrm{H}]^{+}=287$

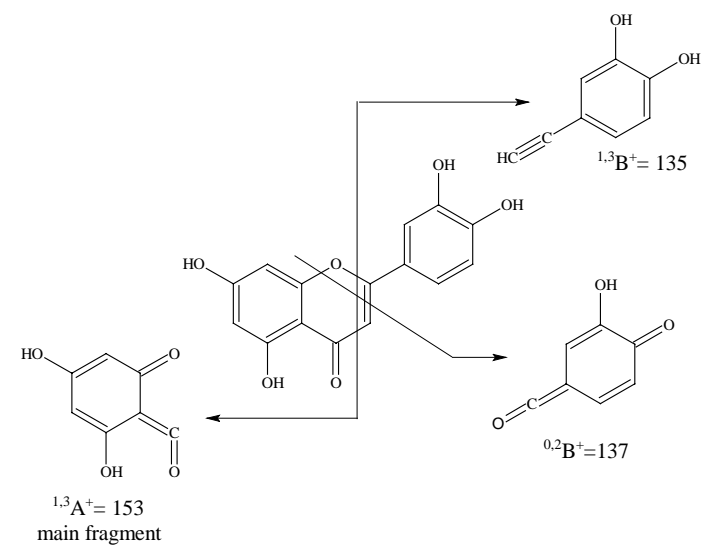

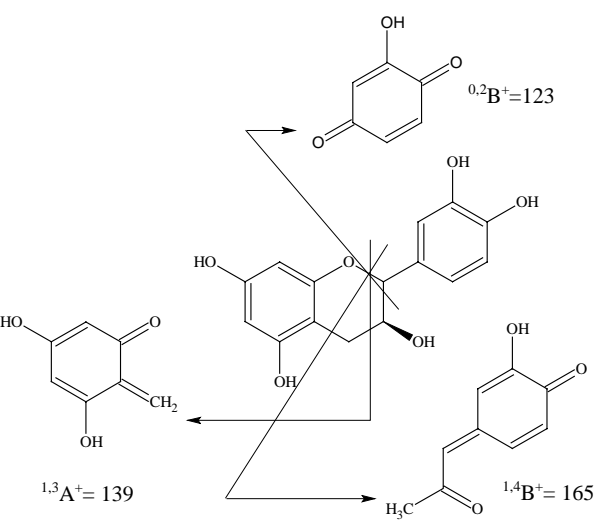

Taxifolin (dihydroflavonol) $[\mathrm{M}+\mathrm{H}]^{+}=305$

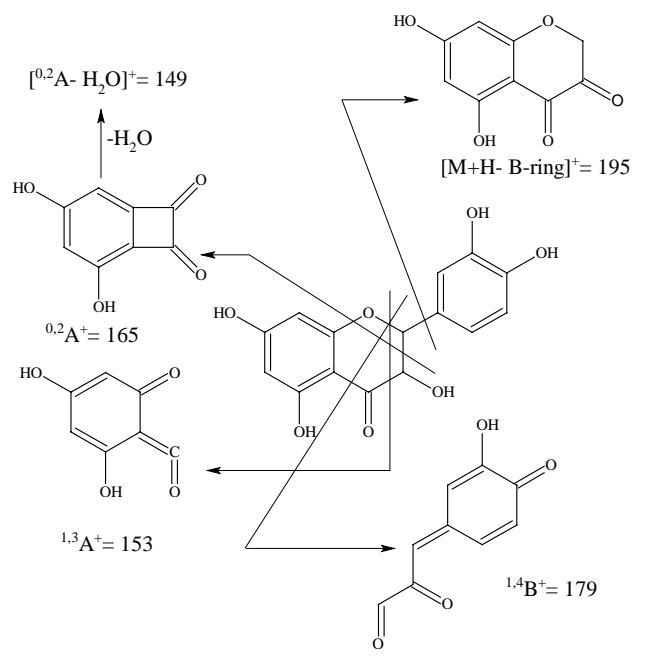

Eriodictyol (flavanone) $[\mathrm{M}+\mathrm{H}]^{+}=289$

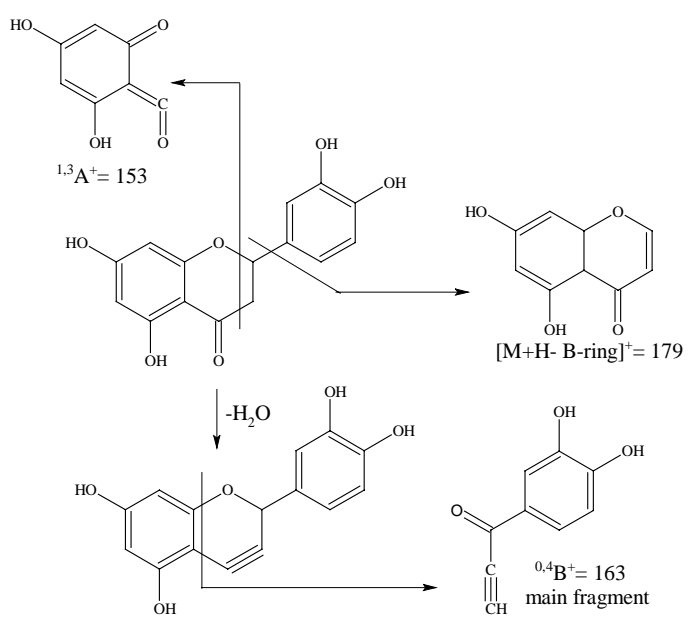


The basic fragments produced by C-ring fission of quercetin are presented in Scheme 1. The respective fragments of the four flavonols are listed in Table 2. In particular, the C-ring fission of fisetin results in ${ }^{0,2} \mathrm{~B}^{+}$and ${ }^{1,3} \mathrm{~A}^{+}$fragments that possess equal $\mathrm{m} / \mathrm{z}=137$ peaks, as well as ${ }^{0,2} \mathrm{~A}^{+}$and ${ }^{1,3} \mathrm{~B}^{+}$ ones with $\mathrm{m} / \mathrm{z}=149$. Therefore, instead of four characteristic fragments, like in the case of quercetin and kaempferol, only two were observed $(\mathrm{m} / \mathrm{z}=137$ and $\mathrm{m} / \mathrm{z}=149)$. Flavonol did not exhibit the ${ }^{1,3} \mathrm{~B}^{+}$ fragment as its formation is associated with the presence of B-ring $o$ - or $p$-hydroxy-substitution. This was also confirmed by the mass spectrum of galangin [11] (another non substituted B-ring flavonol) that did not present the expected ${ }^{1,3} \mathrm{~B}^{+}$fragment at $\mathrm{m} / \mathrm{z}=119$.

On the other hand, flavones $[\mathrm{M}+\mathrm{H}]^{+}$ions exhibited only the $\left[\mathrm{M}+\mathrm{H}-\mathrm{H}_{2} \mathrm{O}\right]^{+},\left[\mathrm{M}+\mathrm{H}-\mathrm{H}_{2} \mathrm{O}-\mathrm{CO}\right]^{+},{ }^{1,3} \mathrm{~A}^{+}$, and ${ }^{1,3} \mathrm{~B}^{+}$fragments, which have also been observed by Boué et al. [6], Ma et al. [14] and Chen et al. [16] in the cases of luteolin, apigenin and baicalein. In the current study ${ }^{0,2} \mathrm{~B}^{+}$was detected in the mass spectra of luteolin and apigenin as a minor fragment, with m/z 137 and 121, respectively, but not in the case of chrysin, which lacks the B-ring hydroxy substitution.

Huck et al. [17] observed that polymethoxylated flavones $[\mathrm{M}+\mathrm{H}]^{+}$primarily lose a methyl group to form $\left[\mathrm{M}+\mathrm{H}-\mathrm{CH}_{3}\right]^{+}$, further dehydrate to $\left[\mathrm{M}+\mathrm{H}-\mathrm{CH}_{3}-\mathrm{H}_{2} \mathrm{O}\right]^{+}$and then lose a carbonyl group. This suggestion can be verified by the MS spectra of cirsimaritin, baicalein-6,7-dimethyl ether, norwogonin-7,8-dimethyl ether, luteolin-7,4'-dimethyl ether and xanthomicrol, which have been presented by other researchers [18-21].

The protonated molecules of the studied flavanones $[\mathrm{M}+\mathrm{H}]^{+}$both dehydrated to give $\left[\mathrm{M}+\mathrm{H}-\mathrm{H}_{2} \mathrm{O}\right]^{+}$ and lost a $\mathrm{CH}_{2} \mathrm{CO}$ group: [M+H-CH$\left.{ }_{2} \mathrm{CO}\right]^{+}$. Equally characteristic for flavanones was the loss of the whole B-ring to produce a [M+H-B-ring $]^{+}$fragment. C-ring 1,3 and 0,4 retrocyclization cleavages occurred, the latter also happening for the dehydration product of the protonated molecule (Scheme 1). The detected fragments were the ${ }^{1,3} \mathrm{~A}^{+}$and ${ }^{0,4} \mathrm{~B}^{+}$. Hughes et al. [11] observed the same fragments from naringenin, while ${ }^{0,4} \mathrm{~B}^{+}$is such a characteristic fragment that has been also observed in prenyl flavanones [22]. The methoxylated flavanone hesperetin exhibited the same fragmentation pattern with eriodictyol. In contrast to the behavior of polymethoxylated flavones the methylation of flavanones (hesperetin compared to eriodictyol) did not affect the fragmentation (Table 2).

Dihydroflavonols (or flavanonols) are isomers of flavanones which display the same UV-Vis spectrum but can be easily distinguished through their mass spectra. We studied taxifolin, which exhibited an initial dehydration of $[\mathrm{M}+\mathrm{H}]^{+}$to $\left[\mathrm{M}+\mathrm{H}-\mathrm{H}_{2} \mathrm{O}\right]^{+}$and sequential losses of two carbonyl groups to form $\left[\mathrm{M}+\mathrm{H}-\mathrm{H}_{2} \mathrm{O}-\mathrm{CO}\right]^{+}$and $\left[\mathrm{M}+\mathrm{H}-\mathrm{H}_{2} \mathrm{O}-2 \mathrm{CO}\right]^{+}$. Additional fragments were the ${ }^{1,3} \mathrm{~A}^{+},[\mathrm{M}+\mathrm{H}-$ B-ring $]^{+},\left[{ }^{0,2} \mathrm{~A}-\mathrm{H}_{2} \mathrm{O}\right]^{+}$and ${ }^{1,4} \mathrm{~B}^{+}$(Scheme 1). Le Gall et al. [23] obtained similar fragments in the mass spectrum of dihydrokaempferol.

Flavanols presented defining C-ring fragments identical to those of the studied flavanones, as can be seen from Table 2. However the high relative abundance of the three main fragments of C-ring fission i.e. ${ }^{1,2} \mathrm{~B}^{+},{ }^{1,3} \mathrm{~A}^{+}$and ${ }^{1,4} \mathrm{~B}^{+}$is a characteristic quality of flavanols, presented even by the methoxylated ones, according to the spectra of Cren-Olivé et al. [24] and they can distinguish these flavonoids from any other subgroup. 
Table 2. The $[\mathrm{M}+\mathrm{H}]^{+}$molecules of the standard flavonoid aglycones, as well as the defining structure fragments produced by $\mathrm{MS}_{2}$.

\begin{tabular}{|c|c|c|c|c|c|c|c|}
\hline \multicolumn{8}{|c|}{ Standard flavonoid aglycones } \\
\hline \multirow{2}{*}{$\begin{array}{l}\text { Assessed } \\
\text { fragments }\end{array}$} & \multicolumn{4}{|c|}{ Flavonols } & \multicolumn{3}{|c|}{ Flavones } \\
\hline & $\begin{array}{c}\text { Quercetin } \\
\text { (1) } \\
\end{array}$ & $\begin{array}{c}\text { Fisetin } \\
(2) \\
\end{array}$ & $\begin{array}{c}\text { Kaempferol } \\
(3) \\
\end{array}$ & $\begin{array}{c}\text { Flavonol } \\
(4) \\
\end{array}$ & $\begin{array}{c}\text { Luteolin } \\
(5) \\
\end{array}$ & $\begin{array}{c}\text { Apigenin } \\
(6) \\
\end{array}$ & $\begin{array}{c}\text { Chrysin } \\
(7) \\
\end{array}$ \\
\hline$[\mathrm{M}+\mathrm{H}]^{+}$ & 303 & 287 & 287 & 239 & 287 & 271 & 255 \\
\hline \multicolumn{8}{|c|}{ Defining subgroup fragments } \\
\hline$\left[\mathrm{M}+\mathrm{H}-\mathrm{H}_{2} \mathrm{O}\right]^{+}$ & $285(69)^{\mathrm{a}}$ & $269(59)$ & $269(39.5)$ & $221(28)$ & $269(36)$ & $253(20)$ & $237(36.5)$ \\
\hline$\left[\mathrm{M}+\mathrm{H}-\mathrm{H}_{2} \mathrm{O}-\mathrm{CO}\right]^{+}$ & $257(100)$ & $241(100)$ & $241(100)$ & $193(31.5)$ & $241(36.5)$ & $225(18)$ & $209(23)$ \\
\hline$\left[\mathrm{M}+\mathrm{H}-\mathrm{H}_{2} \mathrm{O}-2 \mathrm{CO}\right]^{+}$ & $229(42)$ & $213(62)$ & $213(59)$ & $165(64)$ & - & - & - \\
\hline$[\mathrm{M}+\mathrm{H}-\mathrm{CO}]^{+}$ & $275(14)$ & $259(25)$ & $259(32)$ & $211(7)$ & - & - & - \\
\hline$[\mathrm{M}+\mathrm{H}-2 \mathrm{CO}]^{+}$ & $247(30)$ & $231(70)$ & $231(29.5)$ & $183(77)$ & - & - & - \\
\hline$\left[\mathrm{M}+\mathrm{H}-\mathrm{CH}_{2} \mathrm{CO}\right]^{+}$ & - & - & - & - & - & - & - \\
\hline \multicolumn{8}{|c|}{ Defining A- \& B- ring fragments } \\
\hline${ }^{0,2} \mathrm{~A}^{+}$ & $165(35.5)$ & 149 & $165(52)$ & $133(78)$ & - & - & - \\
\hline${ }^{0,2} \mathrm{~B}^{+}$ & $137(11)$ & 137 & $121(21)$ & $105(48)$ & $137(19)$ & $121(7)$ & - \\
\hline${ }^{0,4} \mathrm{~B}^{+}$ & - & - & - & - & - & - & - \\
\hline${ }^{1,2} \mathrm{~B}^{+}$ & - & - & - & - & - & - & - \\
\hline${ }^{1,3} \mathrm{~A}^{+}$ & $153(7)$ & $137(22)$ & $153(27)$ & $121(100)$ & $153(100)$ & $153(100)$ & $153(100)$ \\
\hline${ }^{1,3} \mathrm{~B}^{+}$ & $149(5.5)$ & $149(50)$ & $133(13)$ & - & 135 (17) & $119(18)$ & $102(16)$ \\
\hline${ }^{1,4} \mathrm{~B}^{+}$ & - & - & - & - & - & - & - \\
\hline$\left[{ }^{0,2} \mathrm{~A}-\mathrm{H}_{2} \mathrm{O}\right]^{+}$ & - & - & - & - & - & - & - \\
\hline$[\mathrm{M}+\mathrm{H} \text {-B-ring }]^{+}$ & - & - & - & - & - & - & - \\
\hline
\end{tabular}

\begin{tabular}{|c|c|c|c|c|c|}
\hline \multirow{2}{*}{$\begin{array}{l}\text { Assessed } \\
\text { fragments }\end{array}$} & \multicolumn{2}{|c|}{ Flavanones } & \multirow{2}{*}{$\begin{array}{c}\text { Dihydroflavonol } \\
\text { Taxifolin } \\
(10) \\
\end{array}$} & \multicolumn{2}{|c|}{ Flavanols } \\
\hline & $\begin{array}{c}\text { Eriodictyol } \\
(8)\end{array}$ & $\begin{array}{c}\text { Hesperetin } \\
(9)\end{array}$ & & $\begin{array}{c}(+) \text {-Catechin } \\
(11)\end{array}$ & $\begin{array}{c}\text { (-)-Epicatechin } \\
(12) \\
\end{array}$ \\
\hline$[\mathrm{M}+\mathrm{H}]^{+}$ & 289 & 303 & 305 & 291 & 291 \\
\hline \multicolumn{6}{|c|}{ Defining subgroup fragments } \\
\hline$\left[\mathrm{M}+\mathrm{H}-\mathrm{H}_{2} \mathrm{O}\right]^{+}$ & $271(15.5)$ & $285(11)$ & $287(98)$ & $273(15)$ & $273(16)$ \\
\hline$\left[\mathrm{M}+\mathrm{H}-\mathrm{H}_{2} \mathrm{O}-\mathrm{CO}\right]^{+}$ & - & - & $259(100)$ & - & - \\
\hline$\left[\mathrm{M}+\mathrm{H}-\mathrm{H}_{2} \mathrm{O}-2 \mathrm{CO}\right]^{+}$ & - & - & $231(2)$ & - & - \\
\hline$[\mathrm{M}+\mathrm{H}-\mathrm{CO}]^{+}$ & - & - & - & - & - \\
\hline$[\mathrm{M}+\mathrm{H}-2 \mathrm{CO}]^{+}$ & - & - & - & - & - \\
\hline$\left[\mathrm{M}+\mathrm{H}-\mathrm{CH}_{2} \mathrm{CO}\right]^{+}$ & $247(5)$ & $261(4)$ & - & $249(2)$ & $249(3)$ \\
\hline \multicolumn{6}{|c|}{ Defining A- \& B- ring fragments } \\
\hline${ }^{0,2} \mathrm{~A}^{+}$ & - & - & - & - & - \\
\hline${ }^{0,2} \mathrm{~B}^{+}$ & - & - & - & - & - \\
\hline${ }^{0,4} \mathrm{~B}^{+}$ & $163(100)$ & $177(100)$ & - & - & - \\
\hline $1,2 \mathrm{~B}^{+}$ & - & - & - & $123(91)$ & $123(93)$ \\
\hline${ }^{1,3} \mathrm{~A}^{+}$ & $153(21)$ & $153(13)$ & $153(35)$ & $139(100)$ & $139(100)$ \\
\hline${ }^{1,3} \mathrm{~B}^{+}$ & - & - & - & - & - \\
\hline${ }^{1,4} \mathrm{~B}^{+}$ & - & - & $179(2)$ & $165(77.5)$ & 165 (79) \\
\hline$\left.{ }^{0,2} \mathrm{~A}-\mathrm{H}_{2} \mathrm{O}\right]^{+}$ & - & - & $149(3)$ & - & - \\
\hline$[\mathrm{M}+\mathrm{H} \text {-B-ring }]^{+}$ & $179(20)$ & $179(26)$ & $195(16)$ & - & - \\
\hline
\end{tabular}


According to the aforementioned data the fragmentations of the compounds of each flavonoid subgroup are specific and therefore these fragmentations, combined with the molecular weight of the parent ion, the retention times and the UV spectrum can allow the tentative identification of a compound, which can be further verified by the use of suitable standards, when available. To verify this, we have characterized the major flavonoid aglycons of an Origanum vulgare extract, according to the proposed approach, as presented below.

\section{Identification of oregano flavonoid aglycones}

The HPLC-DAD analysis of oregano diethyl ether extract lead to the separation of four major peaks and several minor ones, as shown in Figure 4. Peak A presented a retention time and spectrum similar to taxifolin, while the MS/MS analysis revealed a molecular ion peak and fragmentation identical to that of this compound (Table 3). Taxifolin was then co-injected with the diethyl ether extract and the HPLC-DAD analysis showed an increase in peak A [25-29].

Figure 4. The chromatogram of oregano ether extract, as monitored by HPLC-DAD at $280 \mathrm{~nm}$.

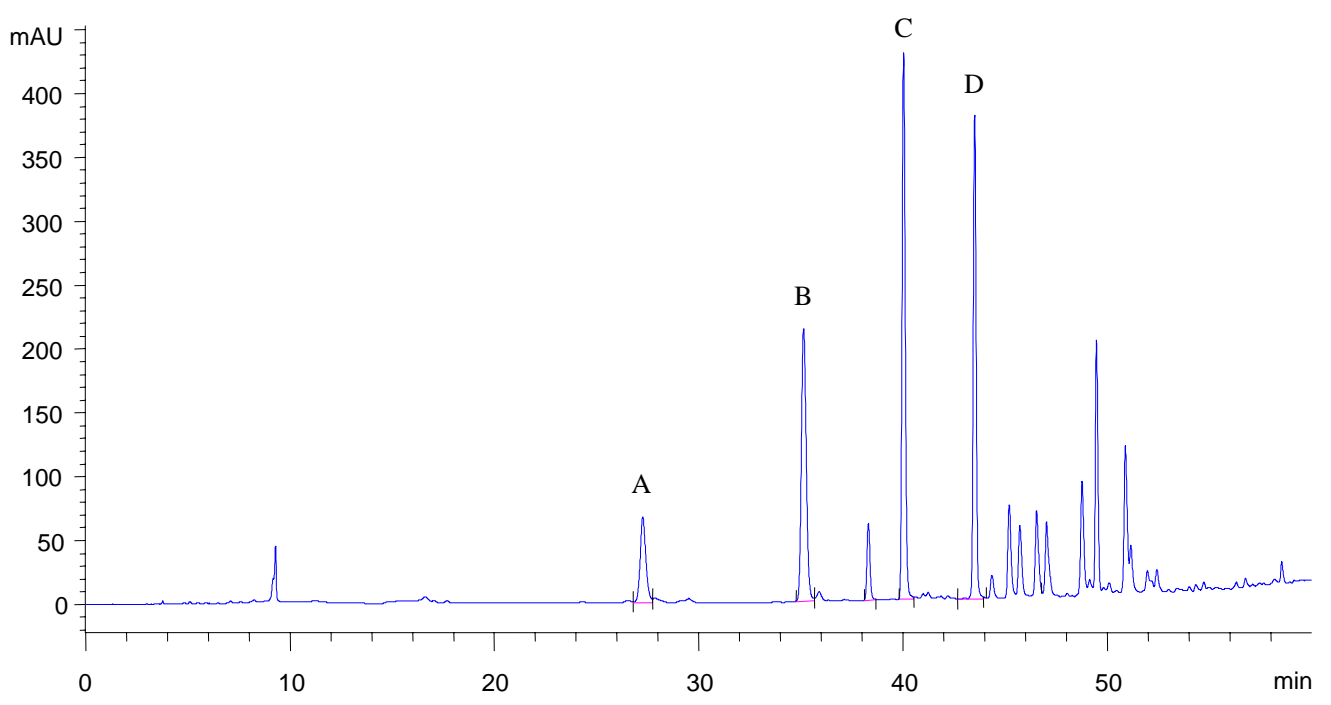

Peak B eluted at 35.1 min and presented a typical flavanone or dihydroflavonol spectrum. The molecular weight of the $[\mathrm{M}+\mathrm{H}]^{+}$ion $(\mathrm{m} / \mathrm{z}=289)$ indicated that it could be a trihydroxy-monomethoxy flavanol, a tetrahydroxy flavanone, or a trihydroxy dihydroflavonol. The subgroup fragments (Table 3) defined the compound as a dihydroflavonol. Compound B has less hydroxyls than taxifolin, a fact that renders it less polar, therefore the higher retention time (than taxifolin) appears reasonable. In dihydroflavonols the C-ring fission fragment with the higher relative abundance is the ${ }^{1,3} \mathrm{~A}^{+}$, so the $33 \% \mathrm{~m} / \mathrm{z}=153$ fragment was assigned to the dihydroxy-substituted A-ring. The second significant fragment in dihydroflavonols is the $[\mathrm{M}+\mathrm{H}-\mathrm{B}-\mathrm{ring}]^{+}$ion, and in the case of peak $\mathrm{B}$ this corresponded to the $\mathrm{m} / \mathrm{z}=195$ (15\%), which further confirmed the dihydroxy-substitution of A-ring. The loss of 94 mass units (B-ring) producing the $[\mathrm{M}+\mathrm{H}-\mathrm{B}-\mathrm{ring}]^{+}$suggested that the compound's $\mathrm{B}$-ring was monohydroxy-substituted. The $\mathrm{m} / \mathrm{z}=163$ (3\%) fragment $\left({ }^{1,4} \mathrm{~B}^{+}\right)$also established the B-ring monohydroxylation with the substituent attached at the C-2' or C-4'. According to the above data compound B was identified as the A-dihydroxy-B-monohydroxy-dihydroflavonol dihydrokaempferol (aromadendrin) [25-29]. 
Peak $\mathrm{C}$ presented a retention time and spectrum similar to that of eriodictyol $\left([\mathrm{M}+\mathrm{H}]^{+}\right.$with $\mathrm{m} / \mathrm{z}=289$, and a fragmentation pattern identical to eriodictyol). The addition of an internal standard confirmed the identity of component $\mathrm{C}$ as eriodictyol [25-30].

Peak D eluted at $43.5 \mathrm{~min}$ and had the typical spectrum of flavanones or dihydroflavonols. Its MS/MS fragmentation was a flavanone type. The protonated molecule $(\mathrm{m} / \mathrm{z}=273)$ differed from that of eriodictyol by 16 mass units, which indicated a trihydroxy-substitution on the flavanone nucleus. The higher retention time of compound $\mathrm{D}$ than eriodictyol is in agreement with the above suggestion. In flavanones the main fragment is the ${ }^{0,4} \mathrm{~B}^{+}$, therefore $\mathrm{m} / \mathrm{z}=147$ (100\%) suggested a monohydroxy-Bring. Compound D thus presented a naringenin-type structure i.e. an A-dihydroxy-B-monohydroxyflavanone $[28,29]$. The identity of compound $\mathrm{D}$ was confirmed to be naringenin by the use of internal standard.

Table 3. The fragmentation of the four flavonoids separated by the HPLC analysis.

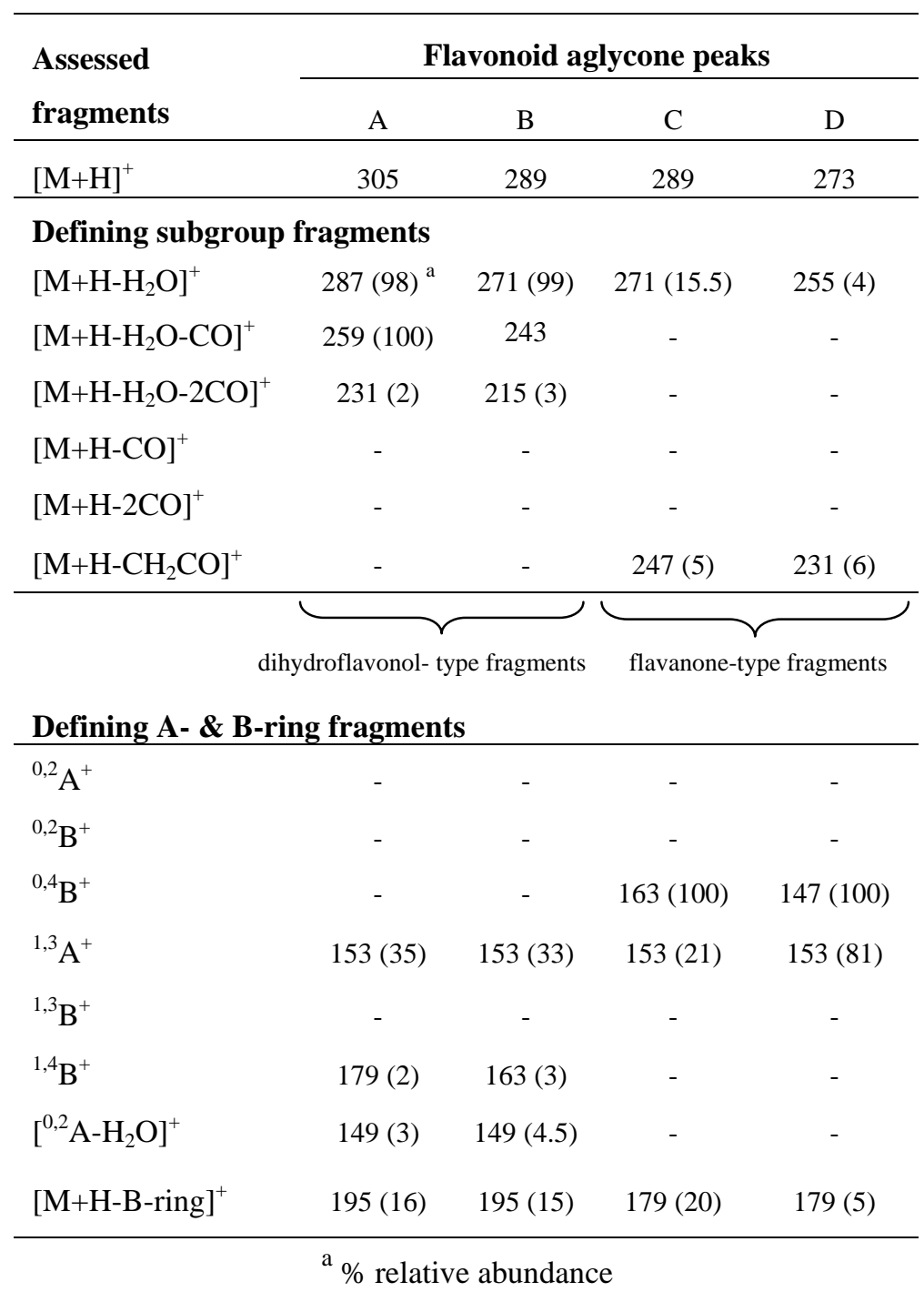

According to the reference curves of eriodictyol, taxifolin and naringenin in the HPLC-DAD system, the concentrations of the three flavonoids in the crude extract were found to be $29.5 \mathrm{mg} / \mathrm{L}$, $85.5 \mathrm{mg} / \mathrm{L}$ and $67.3 \mathrm{mg} / \mathrm{L}$, respectively, corresponding to $232 \mathrm{mg} / \mathrm{kg}, 673 \mathrm{mg} / \mathrm{kg}$ and $530 \mathrm{mg} / \mathrm{kg}$, based on dry plant material. 


\section{Conclusions}

HPLC-ESI-MS/MS in the positive ionization mode enables the direct characterization of flavonoid C-rings from the pattern of dehydration and carbon monoxide losses. The obtained subgroup fragments combined with other spectral characteristics can be used for the identification of the basic nuclei of hydroxylated flavonoid aglycons. They possess $\mathrm{m} / \mathrm{z}$ values close to that of the protonated molecule $\left[\mathrm{M}+\mathrm{H}^{+}\right]$and are distinguished from the second group of diagnostic fragments, with lower $\mathrm{m} / \mathrm{z}$ values. The defining C-ring fragments as well as the A- and B- resulting fragments are typical of each subgroup and can be used as fingerprints for the classification of a compound. The assessment of the classic defining A- and B-ring fragments becomes easier since the flavonoid skeleton is already characterized.

\section{Experimental}

\section{Materials}

The reference compounds (source, purity) used for the MS fragmentation studies were quercetin dihydrate (Fluka 99\%), fisetin hydrate (Aldrich, pure), kaempferol (ItCHEM), flavonol (Sigma), luteolin (Sigma), apigenin (ItCHEM), chrysin (Acros Organics), eriodictyol, naringenin (Extrasynthèse, pure), hesperetin (Sigma), (+)-catechin (Fluka, 98\%), (-)-epicatechin (ItChem) and taxifolin (Sigma). Each standard flavonoid was diluted either in 1:1 acetonitrile-water or in isopropanol at a concentration $4 \cdot 10^{-5} \mathrm{M}$. Origanum vulgare was collected from Agrinio (Greece) during July.

\section{Extraction of oregano flavonoid aglycones}

The dried plant material was ground in a mill (Retch ZM 1, Haan, Germany), equipped with a 0.5 $\mathrm{mm}$ sieve. The ground material (127 g) was extracted in a Soxhlet apparatus with petroleum ether, in order to remove the essential oil and the residue was further extracted with diethyl ether to collect the flavonoid aglycone fraction. The diethyl ether extract was diluted to approximately $0.9 \mathrm{~L}$ with the corresponding solvent, filtered and further diluted to $1 \mathrm{~L}$.

\section{HPLC-DAD Analysis}

The HPLC-DAD method proposed by Merken [31] was used for both standard compounds and the fractions obtained by diethyl ether extraction. The HPLC apparatus consisted of an HP 1100 gradient pump and a diode array detector (Hewlett-Packard, Waldbronn, Germany). A Hypersil $\mathrm{C}_{18}$ column ODS $5 \mu \mathrm{m}, 250$ x $4.6 \mathrm{~mm}$ (MZ Analysentechnik, Mainz, Germany) was used under thermostatted conditions at $30{ }^{\circ} \mathrm{C}$. The solvent system consisted of water (A), methanol (B) and acetonitrile (C), each containing $0.2 \%$ trifluroacetic acid. The initial composition of the mobile phase was $90 \% \mathrm{~A}, 6 \% \mathrm{~B}$ and $4 \% \mathrm{C}$. With linear gradients the composition changed to $85 \% \mathrm{~A}, 9 \% \mathrm{~B}$ and $6 \% \mathrm{C}$ within 5 min, $71 \%$ A, $17.4 \%$ B and $11.6 \%$ C within 30 min, and $0 \%$ A, $85 \%$ B and $15 \%$ C within 60 min. The 
flow rate was maintained at $1 \mathrm{~mL} / \mathrm{min}$. The chromatographic data was processed on a ChemStation for LC 3D software (Agilent Technologies).

\section{MS/MS Analysis}

Each standard compound or separated peak was injected with an ESI source into the mass spectrometer (LCQ-Deca, Thermo-Finnigan, San Jose, USA). The capillary temperature was $200{ }^{\circ} \mathrm{C}$ and the capillary voltage $3.5 \mathrm{kV}$. All data were collected as positive-ion spectra while the MS was performing a full mass scan over the 50-750 range of ; a MS/MS ( $\left.\mathrm{MS}_{2}\right)$ of the most abundant ions was obtained using normalized collision energies of $35 \%$ for flavanones and dihydroflavonols, $45 \%$ for flavonols and $55 \%$ for flavones.

\section{References}

1. Shahidi, F. Flavonoids as Antioxidants; Natural Antioxidants. Chemistry, Health Effects and Practical Applications. AOCS Press: Champaign Illinois, 1997; pp. 174-194.

2. Tsimogiannis, D.I.; Oreopoulou, V. Free-radical scavenging and antioxidant activity of 5,7,3',4'hydroxy-substituted flavonoids. Innov. Food Sci. Emerg. Technol. 2004, 5, 523-528.

3. Dangles, O.; Fargeix, G.; Dufour, C. One-electron oxidation of quercetin and quercetin derivatives in protic and non protic media. J. Chem. Soc, Perkin Trans. 2 1999, 1387-1395.

4. Tsimogiannis, D.; Oreopoulou, V. Defining the role of flavonoid structure on cottonseed oil stabilization: Study of A- and C-ring substitution. JAOCS 2007, 84, 129-136.

5. Tsimogiannis, D.I.; Oreopoulou, V. The contribution of flavonoid C-ring on the DPPH free radical scavenging efficiency. A kinetic approach for the $3^{\prime}, 4^{\prime}$-hydroxy substituted members. Innov. Food Sci. Emerg. Technol. 2006, 7, 140-146.

6. Boué, M.S.; Carter-Wientjes, H.C.; Shih, Y.B.; Cleveland, E.T. Identification of flavone aglycones and glycosides in soybean pods by liquid chromatography-tandem mass spectrometry. J. Chromatogr. A. 2003, 991, 61-68.

7. Bohm, B. Extraction, Purification and Identification of Flavonoids. Introduction to Flavonoids; Harwood Academic Publishers: Amsterdam, The Netherlands, 1998; pp. 200-204.

8. Cuyckens, F.; Claeys, M. Mass spectrometry in the structural analysis of flavonoids. J. Mass Spectrom. 2004, 39, 1-15.

9. Fabre, N.; Rustan, I.; de Hoffmann, E.; Quetin-Leclercq, J. Determination of flavone, flavonol, and flavanone aglycones by negative ion liquid chromatography electrospray ion trap mass spectrometry. J. Am. Soc. Mass Spectrom. 2001, 12, 707-715.

10. March, E.R.; Miao, Xiu-Sheng. A fragmentation study of kaempferol using electrospray quadrupole time-of-flight mass spectrometry at high mass resolution. Int. J. Mass Spectrom. 2004, 231, 157-167.

11. Hughes, J.R.; Croley, R.T.; Metcalfe, D.C.; March, E.R. A tandem mass spectrometric study of selected characteristic flavonoids. Int. J. Mass Spectrom. 2001, 210-211, 371-385.

12. Wu, W.; Yan, C.; Li, L.; Liu, Z.; Liu, S. Studies on the flavones using liquid chromatographyelectrospray ionization tandem mass spectrometry. J. Chromatogr. A 2004, 1047, 213-220. 
13. Wu, W.; Liu, Z.; Song, F.; Liu, S. Structural Analysis of Selected Characteristic Flavones by Electrospray Tandem Mass Spectrometry. Anal. Sci. 2004, 20, 1103-1105

14. Ma, Y.L.; Li, Q.M.; Van den Heuvel, H.; Claeys, M. Characterization of flavone and flavonol aglycones by collision-induced dissociation tandem mass spectrometry. Rapid Commun. Mass Spectrom. 1997, 11, 1357-1364.

15. Huck, C.W.; Buchmeiser, M.R.; Bonn, G.K. Fast analysis of flavonoids in plant extracts by liquid chromatography-ultraviolet absorbance detection on poly(carboxylic acid)-coated silica and electrospray ionization tandem mass spectrometric detection. J. Chromatogr. A 2001, 943, 33-38.

16. Chen, L. J.; Games, D. E.; Jones, J.; Kidwell, H.; Separation and Identification of Flavonoids in an Extract from the Seeds of Oroxylum indicum by CCC. J. Liq. Chromatogr. Relat. Technol. 2003, 26, 1623-1636.

17. Huck, W.C.; Huber, G.C.; Ongania, K.H.; Bonn, K.G. Isolation and characterization of methoxylated flavones in the flowers of Primula veris by liquid chromatography and mass spectrometry. J. Chromatogr. A 2000, 870, 453-462.

18. Hasrat, J. A.; Pieters, L.; Claeys, M.; Vlietinck A. Adenosine-1 Active Ligands: Cirsimarin, a Flavone Glycoside from Microtea debilis. J. Nat. Prod. 1997, 60, 638-641.

19. Stevens, J. F.; Ivancic, M.; Deinzer, M. L.; Wollenweber, E. A Novel 2-Hydroxyflavanone from Collinsonia Canadensis. J. Nat. Prod. 1999, 62, 392-394.

20. Lai, Jia-Ping; Lim, Yew Heng; Su, Jin; Shen, Han-Ming, Ong, Choon Nam. Identification and characterization of major flavonoids and caffeoylquinic acids in three Compositae plants by LC/DAD-APCI/MS. J. Chromatogr. B 2007; in press (corrected proof).

21. Grayer, R. J.; Kite, G. C.; Abou-Zaid, M.; Archer, L. J. The Application of Atmospheric Pressure Chemical Ionisation Liquid Chromatography- Mass Spectrometry in the Chemotaxonomic Study of Flavonoids: Characterisation of Flavonoids from Ocimum gratissimum var. gratissimum. Phytochem. Anal. 2000, 11, 257-267.

22. Stevens, F.J.; Taylor, W.A.; Deinzer, L.M. Quantitative analysis of xanthohumol and related prenylflavonoids in hops and beer by liquid chromatography-tandem mass spectrometry. $J$. Chromatogr. A 1999, 832, 97-107.

23. Le Gall, G.; DuPont, M.S.; Mellon, A.F.; Davis, L.A.; Collins, J.G.; Verhoeyen, E.M.; Colquhoun, J.I. Characterization and Content of Flavonoid Glycosides in Genetically Modified Tomato (Lycopersicon esculentum) Fruits. J. Agric. Food Chem. 2003, 51, 2438-2446.

24. Cren-Olivé, C.; Déprez, S.; Leburn, S.; Codeville, B.; Rolando, C. Characterization of methylation site of monomethylflavan-3-ols by liquid chromatography/electrospray ionization tandem mass spectrometry. Rapid Commun. Mass Spectrom. 2000, 14, 2312-2319.

25. Tsimogiannis, D.; Stavrakaki, M.; Oreopoulou, V. Isolation and characterisation of antioxidant components from oregano (Origanum heracleoticum). Int. J. Food Sci. Technol. 2006, 41 (Supplement 1), 39-48.

26. Vekiari, S.A.; Oreopoulou, V.; Tzia, C.; Thomopoulos, C.D. Oregano flavonoids as lipid antioxidants. JAOCS 1993, 70, 483-487.

27. Bocchini, P.; Russo, M.; Galletti, G.C. Pyrolysis - gas chromatography/mass spectrometry used as a microanalytical technique for the characterization of Origanum heracleoticum from Calabria, Southern Italy. Rapid Commun. Mass Spectrom. 1998, 12, 1555-1563. 
28. Cavero, S.; Garcia-Risco, M.R.; Marin, F.R.; Jaime, L.; Santoyo, S.; Senorans, F. J.; Reglero, G.; Ibanez, E. Supercritical fluid extraction of antioxidant compounds from oregano. J. Supercrit. Fluids 2006, 38, 62-69.

29. Exarchou, V.; Godejohann, M.; Van Beek, T.A.; Gerothanassis, I.P.; Vervoort, J. LC-UV-SolidPhase Extraction-NMR-MS Combined with a Cryogenic Flow Probe and its Application to the Identification of Compounds Present in Greek Oregano. Anal. Chem. 2003, 75, 6288-6294.

30. Kosar, M.; Dorman, H.J.D.; Hiltunen, R. Effect of an acid treatment on the phytochemical and antioxidant characteristics of extracts from selected Lamiaceae species. Food Chem. 2005, 91, 525-533.

31. Mercken, H.M.; Beecher, G.M. Liquid chromatographic method for the separation and quantification of prominent flavonoid aglycones. J. Chromatogr. A 2000, 897, 177-184.

Sample availability: Samples are available from the authors.

(C) 2007 by MDPI (http://www.mdpi.org). Reproduction is permitted for noncommercial purposes. 